\title{
Additional Chemotherapy During Resting Periods After Preoperative Chemoradiotherapy in Patients With Rectal Cancer
}

\author{
Ok Suk Bae \\ Department of Surgery, Keimyung University Dongsan Medical Center, Keimyung University School of Medicine, Daegu, Korea
}

\section{See Article on Page 192-197}

The advantages of preoperative chemoradiotherpy are tumor downstaging and to minimize seeding of tumor cells during surgery, but it has two problems awaiting solution. The first problem is low rate of complete response. Rectal cancer is known to be radioresistant compared with anal cancer. If a higher response rate is to be obtained, a concomitant chemotherapy method is needed because chemotherapy sensitizes tumor cells to radiation. The second problem is the long treatment time, including the resting time after completion of chemoradiation, because surgery is performed approximately after 6 weeks following the completion of chemoradiotherapy. Because cancer will not be treated during the resting time, some are apprehensive about the dangers of cancer being aggravated and metastatic lesions from remnant cancer occurring during the resting time. I support the conclusion that additional chemotherapy is one of the methods to resolve these problems in spite of these demerits. If additional chemotherapy can downstage a tumor more than conventional chemoradiation, it will be a very useful treatment method for rectal cancer patients. In this article, authors report that they tried an additional four weeks of chemotherapy with capecitabine during resting periods. They did not obtain a visibly better result; nonetheless, this article bears prospective meanings [1].

Fontana [2] reported encouraging results for preoperative 5-FUoxaliplatin chemoradiation therapy in locally advanced rectal can-

Correspondence to: Ok Suk Bae, M.D.

Department of Surgery, Keimyung University Dongsan Medical Center, Keimyung University School of Medicine, 56 Dalseong-ro, Jung-gu,

Daegu 700-712, Korea

Tel: +82-53-250-7308, Fax: +82-53-250-7322

E-mail: oksukbae@dsmc.or.kr

(C) 2013 The Korean Society of Coloproctology

This is an open-access article distributed under the terms of the Creative Commons Attribution NonCommercial License (http://creativecommons.org/licenses/by-nc/3.0) which permits unrestricted noncommercial use, distribution, and reproduction in any medium, provided the original work is properly cited. cer. In the near future, new drugs and molecular studies will be developed, and these may lead to much better results [3]. Therefore, additional study will be needed to realize improvements in preoperative control for rectal cancer. I envisage that future patients with rectal cancer will get much benefit from additional chemotherapy and that a small number of them will be cured without surgery.

\section{REFERENCES}

1. Lee KH, Song MS, Park JB, Kim JS, Kang DY, Kim JY. A phase II study of additional four-week chemotherapy with capecitabine during the resting periods after six-week neoadjuvant chemoradiotherapy in patients with locally advanced rectal cancer. Ann Coloproctol 2013;29:192-7.

2. Fontana E, Pucci F, Camisa R, Bui S, Galdy S, Leonardi F, et al. Long-term results of preoperative 5-fluorouracil-oxaliplatin chemoradiation therapy in locally advanced rectal cancer. Anticancer Res 2013;33:725-30.

3. Kheirelseid EA, Miller N, Chang KH, Curran C, Hennessey E, Sheehan M, et al. miRNA expressions in rectal cancer as predictors of response to neoadjuvant chemoradiation therapy. Int J Colorectal Dis 2013;28:247-60. 